\title{
0 monitor do Programa Mais Educação: em busca de uma definição conceitual
}

\author{
Neuda Alves do Lago* \\ Tauã Carvalho de Assis* * \\ DOI: $10.1590 / 0103-7307201607907$
}

\section{Resumo}

Este trabalho debate a caracterização da literatura sobre os educadores que se dedicam às práticas educativas não escolares, especificamente os monitores das escolas municipais de JataíGO que atuam no Programa Mais Educação. Buscou-se compreender o monitor como educador social inserido nas práticas educativas não formais promovidas pela implementação do Programa Mais Educação, bem como a terminologia empregada, o campo de trabalho, as atividades desenvolvidas e a formação desse profissional. A construção metodológica desta compreensão utilizou-se de aportes teóricos vários e do estudo comparado da revisão da literatura com os documentos oficiais do programa. Com a finalidade de comprovar ou contestar o encontrado na pesquisa bibliográfica, elaboraram-se questões abertas e fechadas, as quais todos os monitores atuantes no Programa Mais Educação das escolas municipais de Jataí-GO responderam. Apresentam-se aqui os dados obtidos. Por meio da pesquisa bibliográfica, documental e da análise dos dados, é possível afirmar que os monitores podem ser entendidos como educadores sociais e são uma categoria que ainda se encontra entre tensões e indefinições, na busca da construção de sua identidade como grupo profissional.

Palavras-chave: Programa Mais Educação, monitor, educador social
* Universidade Federal de Goiás (UFG), Faculdade de Letras, Goiânia, G0, Brasil. neuda@ufg.br

* * Secretaria Municipal de Educação de Jataí - Goiás, Coordenação de Educação Integral; Jataí, G0, Brasil. Universidade Federal de Goiás - UFG, Goiânia, G0, Brasil.tauacarvalho@ hotmail.com 


\title{
The monitor of the Program More Education: towards a conceptual definition
}

\begin{abstract}
This paper discusses the literature on educators who are dedicated to non-school educational practices, specifically monitors that operate in the More Education Program. We seeked to understand the 'monitor' as a 'social educator' inserted in the non-formal educational practices promoted by the implementation of the More Education Program as well as the terminology used in the documents, the job market, the activities developed and the training of these professionals. Based on the litterature, the programme official documents and data analysis of the Jataí-Goiás-Brazil monitors survey, it became clear that the monitors can be understood as social educators who still face uncertainties and tensions as they try to build their identity as a professional group.
\end{abstract}

Keywords: More Education Program, monitor, social educator 


\section{Um breve panorama}

O Programa Mais Educação (PME), lançado em 2008, surgiu no bojo do debate de políticas públicas como o “Compromisso Todos pela Educação” e o “Plano de Desenvolvimento da Educação" (PDE), que previam a implementação da educação integral em jornada ampliada (Ministério da Educação e Cultura - MEC, 2011).

Entre os objetivos do PME, figuram os seguintes: “I - formular política nacional de educação básica em tempo integral; II - promover diálogo entre os conteúdos escolares e os saberes locais" (Decreto BR nำ7.083, 2010, p. 2). Ainda nesse mesmo documento, o Ministério da Educação (MEC) definiu educação básica em tempo integral como jornada escolar de, no mínimo, sete horas diárias, de forma a constituir uma extensão do período em que o aluno já estava em sala de aula.

Com a finalidade de concretizar essa ampliação, foi proposta, por meio do PME, uma gama de atividades/oficinas que têm por objetivo complementar a jornada escolar com atividades diversificadas nos macrocampos (grandes áreas) de acompanhamento pedagógico: comunicação, uso de mídias e cultura digital e tecnológica; cultura, artes e educação patrimonial; educação ambiental, desenvolvimento sustentável e economia solidária e criativa/educação econômica; esporte e lazer (MEC, 2013).

Para atuar nessas atividades/oficinas no Programa Mais Educação, surgiu a figura do monitor. Ele é o agente responsável por fomentar o debate dos saberes escolares com os saberes comunitários, conforme explicitado no objetivo II. Esse agente, introduzido pelo Programa Mais Educação e pela estratégia de ampliação da jornada escolar, é o objeto de estudo deste trabalho e de nossa investigação.

Quem, afinal, é o monitor explicitado no PME? Essa será a pergunta central deste trabalho. Com fins de cumprir o objetivo traçado, utilizaremos a revisão da literatura, buscando o termo e colocando-o a serviço de uma interpretação dentro de sua atuação no Programa Mais Educação. Fundamentaremos concretamente nossa discussão com a apresentação de dados dos monitores que atuam no PME no município de Jataí, do estado de Goiás, na Região Centro-Oeste do Brasil.

Dividiremos este estudo em dois aspectos centrais: buscar a compreensão do educador que atua no PME; e ilustrar a especificidade dessa ocupação, se ela existir. Para a elaboração dessa compreensão, utilizamos como fundamento teórico os estudos de Garcia (2008); Gohn (2010); Libâneo (2010); Maraschin, Chassot e Gorczevski (2006); e Ude (2014) e depois recorremos ao estudo comparativo desses 
com os documentos oficiais do programa. Nesta primeira parte do artigo, fizemos a opção metodológica de contrastar a pesquisa bibliográfica com a pesquisa documental.

Com vistas a confirmar ou a negar as hipóteses apresentadas no texto, elaboramos um questionário, com perguntas fechadas e abertas, às quais responderam todos os monitores do Programa Mais Educação de Jataí, no sudoeste goiano. Esses dados nos serviram de base concreta, ao procedermos à análise central deste trabalho: a busca da compreensão do monitor como educador social, tal qual aparece na literatura específica e nos documentos governamentais. Assim, na segunda parte deste trabalho, apresentaremos os dados coletados, a partir do instrumento questionário, e os confrontaremos com o disposto na literatura.

\title{
2. 0 monitor retratado na literatura: definições ou indefinições? Libâneo (2010) afirma que
}

\begin{abstract}
todo educador sabe, hoje, que as práticas educativas ocorrem em muitos lugares, em muitas instâncias formais, não-formais, informais. Elas acontecem nas familias, nos locais de trabalho, na cidade e na rua, nos meios de comunicação e, também, nas escolas. Não é possível mais afirmar que o trabalho pedagógico se reduz ao trabalho docente nas escolas. (p. 14)
\end{abstract}

O autor inicia sua reflexão com as práticas educativas que só deságuam na escola no final da frase. Ao fazer isso, nos remete a uma ideia explícita: a ação educativa está em todo lugar, fora da escola e também dentro da escola. Isso fica claro na divisão da educação em dimensões distintas, exposta acima, evidenciando a "complexidade e multimensionalidade do fenômeno educativo" (Libâneo, 2010, p. 69), constatação clara de que os muros da escola não retêm o saber total historicamente produzido pela humanidade e por uma comunidade.

O Programa Mais Educação é uma proposta de interdependência, ou melhor, de sinergia, entre os saberes formais/escolares e os saberes informais/não formais / comunitários/populares. Como prática educativa da dimensão não formal, o PME tem intencionalidade e, como programa de governo, ele é institucionalizado, normatizado por resoluções, manuais e por publicações oficiais. Tal constatação nos é possível pelas passagens a seguir, extraídas dos documentos do programa: “É necessário promover maior articulação entre as atividades desenvolvidas no campo da educação 
formal, pelos estabelecimentos de ensino e órgãos de gestão - e os demais setores - saúde, cultura, esporte, lazer, justiça, assistência social, entre outros” (MEC, 2009, p. 45) e "a escola poderá ser afetada positivamente, pelas práticas comunitárias, pela liberdade e autonomia presentes nos espaços de educação informal, pela concretude e pelo movimento da vida cotidiana" (MEC, 2009, p. 31). Assim, apreendemos que a visão institucional é a da escola como espaço de educação formal, e os demais setores pertencem aos espaços de educação informal.

Podemos atestar, por meio da literatura, a invisibilidade da figura e da ocupação do educador nos projetos e nos programas, com raras exceções que apresentaremos aqui. Via de regra, não se sabe quem é ele, o que sabe, o que faz, e como faz o que sabe.

Empregaremos o termo "projetos sociais" para representar o conjunto heterogêneo de programas e projetos, governamentais e do terceiro setor, que se ocupam com as práticas educativas. Os projetos sociais são, portanto, o campo profícuo da atuação dos educadores que se dedicam às práticas educativas não escolares. Assim, trataremos do coletivo dessas práticas educativas projetadas e, portanto, intencionais e situadas no campo da educação não formal, de igual maneira.

Em busca de uma definição da figura dos educadores que se dedicam às práticas educativas não escolares, e em especial os que atuam no PME, encontramos muitas indefinições. As nomenclaturas utilizadas são diversas: monitor, voluntário, oficineiro, oficinista, agente cultural, educador, arte-educador, educador de rua e educador social. E podem existir mais:

Essa discussão não se refere apenas à nomenclatura utilizada, mas a diferentes concepções que os Projetos têm de sua ação e atuação e a existência de diferentes projetos políticos, além de ser uma discussão importante ao considerarmos esse grupo como pertencente a uma categorial profissional que vem, construindo sua identidade nos encontros/ conflitos/ trocas/ entrechoques de diferentes áreas do saber. (Garcia, 2008, p. 87)

Garcia (2008) nos remete a várias reflexões importantes relativas à nomenclatura dada à figura dos educadores que atuam nos projetos sociais. 0 que está em voga não é somente a atividade que esse educador desempenha, mas, além disso, sua identidade como trabalhador inserido em um projeto político de ação educativa.

Também de fundamental importância é a reflexão relativa à construção da identidade desses educadores como categoria profissional, que, segundo a autora, se desenrola na diversidade de diferentes saberes. Isso porque os educadores dos pro- 
jetos sociais atuam com diferentes saberes e práticas: skate, grafite, música, dança, artes marciais, artes plásticas, contação de histórias, percussão, entre tantos outros. Essa multiplicidade de fazeres se traduz em diferentes conteúdos, metodologias, processos educativos e definições.

Sem pretender esgotar a discussão taxonômica, se faz necessária uma maior delimitação de quem seja, então, esse profissional. Neste trabalho, adotaremos “educador social" como representativo do conjunto de termos para nomear os educadores que atuam nos projetos sociais.

Tal eleição não se dá ao acaso, mas, pelo contrário, objetiva focalizar a multiplicidade de visões de um mesmo profissional, com vistas a explicar e a compreender sua posição e atuação e, nomeadamente, a dos monitores inseridos no Programa Mais Educação. Portanto, o monitor retratado nos documentos do PME será aqui sinônimo de educador social. Essa aproximação não é inédita, já tendo sido realizada por Maraschin, Chassot e Gorczevski (2006), que utilizaram o termo “educador social” como representativo de “oficineiros", e por Gohn (2010), que indica que o "educador social” tem atuado também em escolas públicas de tempo integral. É importante ressaltar que tal aproximação entre as atividades desenvolvidas pelos monitores e a definição de educador social não é feita pelo órgão responsável, o Ministério da Educação, mas representa nossa interpretação, apoiada nos autores acima. É este o objetivo do artigo: constatar a definição de educador social e pesquisar se ela se encaixa no que é proposto no PME. De fato, os documentos oficiais hora nenhuma fazem referência ao termo "educador social”, e, para isso, temos uma hipótese: ele é o único que aparece no catálogo de ocupações do Ministério do Trabalho. Portanto, definir que o monitor que atua em um programa oficial do governo federal desempenha uma das ocupações registradas geraria ônus e direitos trabalhistas garantidos por lei. Mas, ao contrário, o PME parte da proposta do monitor como oficineiro, nomenclatura não inclusa no Cadastro Brasileiro de Ocupações, o que autoriza a não geração de direitos trabalhistas a eles, uma vez que não é uma atividade regulamentada.

Gohn (2010) nos apresenta uma definição do que seja o educador social:

é algo mais que um animador cultural, embora ele também deva ser um animador do grupo. Para que ele exerça um papel ativo, propositivo e interativo, ele deve continuamente desafiar o grupo de participantes para a descoberta dos contextos onde estão sendo construídos os textos (escritos, falados, gestuais, gráficos, simbólicos etc.). (pp. 50-51) 
A pesquisadora elucida o perfil do educador social como aquele que desvela os contextos da produção do texto, em caráter dialógico com a comunidade, estando ele também inserido nessa comunidade/territorialidade. Sua ação se dá pela mediação e interação ativa com os membros do grupo, com vistas à reconstrução do tecido social existente (Gohn, 2010).

Outra dificuldade rumo a um consenso identitário como categoria profissional é fruto de outra diversidade: qual a formação desses educadores? Ela é múltipla:

Muitos educadores sociais não apresentam uma formação técnica, até mesmo em nível médio, e atuam em atividades educativas variadas, como animação sociocultural. Por outro lado, profissionais de diferentes áreas acadêmicas, como advocacia, psicologia, assistência social, geografia, filosofia, entre outras, exercem a função de educadores sociais. (Ude, 2014, p. 67)

Não há, entre os educadores sociais, seja como indivíduos, seja como categoria profissional, a delimitação de uma formação específica ou, mesmo, de um nível de formação. De tal modo, pode haver licenciados e bacharéis e, entre eles, pedagogos; universitários e estudantes do Ensino Médio; bolsistas de pesquisa e/ou extensão; ou voluntários.

Enfim, o Programa prevê qualquer formação, de qualquer nível. Essa indefinição é, em si mesma, uma definição, uma vez que a ocupação “educador social” faz parte da Classificação Brasileira de Ocupações do Ministério do Trabalho e Emprego (MTE) do Brasil. É curioso notar, em uma breve pesquisa no site do órgão, a inexistência dos outros termos que geralmente são utilizados para representar a figura do educador nos projetos sociais, como "monitor" e "oficineiro".

O educador social, no documento citado do MTE (2010)르, figura entre os trabalhadores de atenção, defesa e proteção a pessoas em situação de risco, sob o código 5153-05, equiparado a outras ocupações entendidas como de mesmo fim. Transcrevemos, a seguir, partes do documento (Ministério do Trabalho e Emprego, 2010):

\section{TÍTULO}

5153-05 Educador social - Arte educador; Educador de rua; Educador social de rua; Instrutor educacional; Orientador sócio-educativo.
1. Cumpre ressaltar que a inclusão da atividade no CBO é fruto do Projeto de Lei $\mathrm{n}^{0} \mathbf{5 . 3 4 6}$, de 2009, de autoria do Deputado Chico Lopes. 0 projeto de lei teve por inspiração o Marco conceitual das competências do educador social, documento redigido em Montevidéu, em 18 de novembro de 2005. (Recuperado de: <http://aeessp.xpg. uol.com.br/marcoconceitual.htm>). 
5153-10 Agente de ação social - Agente de proteção social; Agente de proteção social de rua; Agente social.

\section{DESCRIÇÃO SUMÁRIA}

Visam garantir a atenção, defesa e proteção a pessoas em situações de risco pessoal e social. Procuram assegurar seus direitos, abordando-as, sensibilizando-as, identificando suas necessidades e demandas e desenvolvendo atividades e tratamento.

\section{FORMAÇÃO E EXPERIÊNCIA}

0 acesso às ocupações da família ${ }^{2}$ é livre sem requisitos de escolaridade. Para a ocupação de conselheiro tutelar ${ }^{3}$ observa-se uma diversidade bastante acentuada no que diz respeito à escolaridade, que pode variar de ensino fundamental incompleto a superior completo.

\section{CONDIÇÕES GERAIS DE EXERCÍCIO}

0 trabalho é exercido em instituições ou nas ruas. As atividades são exercidas com alguma forma de supervisão, geralmente em equipes multidisciplinares. 0s horários de trabalho são variados: tempo integral, revezamento de turno ou períodos determinados. 0s trabalhores [sic] desta familia ocupacional lidam diariamente com situações de risco, assistindo indivíduos com alteração de comportamento, agressividade e em vulnerabilidade. (p. 778)

As ocupações mencionadas compreendem a seção 5153 do CBO do MTE (2010), porém, em pesquisa direta no site, no link “Consulta CBO”, eis que surge, dentro dessa família ocupacional, mais um termo, que também transcrevemos:

2. Aqui cabe uma explicação. A palavra "família" aparece como representativa do conjunto dos trabalhadores do grupo 5153. Com fins de chamar atenção aos itens referentes ao debate proposto neste trabalho, omite dois trabalhadores que figuram também nesta família: "Monitor de dependente químico" (5153-15) e "Conselheiro tutelar" (5153-20).

3. Mantivemos aqui a citação da ocupação "Conselheiro tutelar", a fim de representar a variação de formações que essa família ocupacional permite.

4. Recuperado em 5 de maio de 2014, de http://www. mtecbo.gov.br/cbosite/pages/pesquisas/BuscaPorTituloResultado.jsf

\section{Títulos}

...

\section{3-25 -}

\section{Sócioeducador}

Agente de apoio socioeducativo, Agente de segurança socioeducativa, Agente educacional, Atendente de reintegração social. ${ }^{4}$ 
A família ocupacional 5153 possui extensões gigantescas, uma vez que não conseguimos delimitar facilmente seu campo de atuação. Uma primeira dificuldade surge da natureza do agrupamento proposto pelo MTE, que não nos permite inferir - não sem muito esforço e pesquisas outras - a especificidade do campo de trabalho do educador social. Esses profissionais, os educadores sociais, são/estão incluídos na família entre os "trabalhadores de atenção, defesa e proteção a pessoas em situação de risco", segundo o documento CBO/MTE (2010), disponível para download no site do MTE5. Porém, em pesquisa no próprio site, ${ }^{6}$ aparece uma denominação familiar um pouco diferente, a saber: “5153: Trabalhadores de atenção, defesa e proteção a pessoas em situação de risco e adolescentes em conflito com a lei”. Tais definições nos apontam, entretanto, que a atuação profissional desse trabalhador está ligada a vulnerabilidade, precariedade, situação de risco, conflito com a lei, reintegração social e prevenção. É impossível não notarmos a vinculação a ações educativas que sejam preventivas, ao menos no nome, evitando o conflito com a lei. Maraschin, Chassot e Gorczevski (2006) também refletem sobre o contexto da pobreza e sobre a dificuldade que causa à elaboração das políticas públicas: “As circunstâncias de vida dos jovens brasileiros, principalmente aqueles que vivem em comunidades com insuficientes condições materiais apresentam uma série de desafios às políticas públicas e às instituições sociais" (p.287).

Outra problemática que nos guia neste trabalho é a natureza específica desses trabalhadores. Alguns nomes nos dão pistas: educador, instrutor, orientador e agente. Mas o que seriam essas categorizações? O caráter taxonômico desses trabalhadores indica dinâmica, movimento, mudança, transformação. Assim, eles são tomados como agentes de mudança, visto que cabe a eles identificar demandas e ofertar tratamentos a essas demandas. 0 perfil traçado sugere ainda que esse profissional, acentuadamente caracterizado como "social", tenha ligação direta com a comunidade/ público/território em que atue. Para realizar trabalho de tal envergadura, o educador social precisa conhecer a realidade de seu público-alvo e, mais ainda, compreender essa realidade, ou seja, vivenciá-la ele também.

Enfrentamos outra dificuldade, agora de natureza espacial. Onde, afinal, é o espaço de trabalho dessas ocupações? 0 texto oficial nos traz que esse trabalho é "exercido em instituições ou nas ruas", mas deixa de dizer em quais instituições, se

5. Link para download dos três volumes do Cadastro Brasileiro de Ocupações (2010) no site do Ministério do Trabalho e Emprego do Brasil: http://www.mtecbo.gov. $\mathrm{br} / \mathrm{cbosite/pages/downloads.jsf.}$

6. Link de "Consulta CBO" no site do Ministério do Trabalho e Emprego do Brasil: http://www.mtecbo.gov.br/ cbosite/pages/home.jsf. 
são de Estado ou não governamentais, e, se governamentais, quais são elas. Quando o documento não explicita um local específico, aceitam-se todos os tipos de locais. Conforme Ude (2014), “não se trata de uma postura anti-escola, mas uma proposta que visa articular os processos escolares às questões sociopolíticas e à vida comunitária dos sujeitos” (p. 71). Essa escrita de Ude (2014) nos remete aos propósitos do Programa Mais Educação de configuração de saberes múltiplos do campo escolar e da comunidade. Tendo o registro do CBO e esse autor como fundamentos, entendemos que as atividades do educador social podem ou não ser desenvolvidas na escola e/ou no âmbito de sua coordenação. Ramos e Roman (2011) expõem a atuação de diversos professores em sala de aula como educadores sociais e de seus processos formativos. Portanto, a aproximação e a presença de educadores sociais na escola não representam uma impossibilidade, mas a possibilidade de uma articulação específica de saberes.

O caráter preventivo da atuação desses trabalhadores se revela ao referenciar seu público-alvo de atuação, nos documentos oficiais: "indivíduos com alteração de comportamento, agressividade e em vulnerabilidade" e "reintegração social”. Tais indicações levam-nos a concluir, segundo as inferências documentais, que o trabaIho do educador/agente/instrutor/orientador é de natureza educativo-preventiva. $\mathrm{A}$ natureza das atividades do educador social parece se afastar da escola, e de sua finalidade pedagógica, e assumir um caráter de proteção/assistência social. Entretanto, assim está escrito no documento referência do PME (MEC, 2009):

Além de prever a ampliação do Ensino Fundamental para tempo integral, a Lei no 9.394/96 admite e valoriza as experiências extraescolares (Art. $3^{\circ}$, inciso X), as quais podem ser desenvolvidas com instituições parceiras da escola. De acordo com Guará (2006), essas indicações legais correspondem tanto às expectativas de ampliação do tempo de estudo ou da jornada escolar, dentro do Sistema Público de Ensino, quanto ao crescente movimento de participação de outras organizações nascidas, em geral, por iniciativa da própria comunidade e que trabalham na interface educação-proteção social. (pp. 21-22)

O documento oficial do PME, editado e publicado pelo MEC, aponta que as organizações parceiras das políticas de ampliação do tempo escolar são aquelas que trabalham na interface educação-proteção social. 0 documento recomenda ainda que 
as escolas tenham registradas as ações em seus Projetos Pedagógicos, a fim de não caírem simplesmente na prática da proteção social (MEC, 2009). Maraschin, Chassot e Gorczevski (2006) também refletem sobre tal prática:

0 público usual dos oficineiros são jovens considerados "vulneráveis" ou "em situação de risco", e as oficinas são frequentemente vistas (pelas políticas públicas e pelos próprios oficineiros) como formas de oferecer alternativas a este jovem, afastando-o das drogas, do crime, aumentando seu envolvimento com a comunidade, sua auto-estima, estimulando a criatividade, a crítica social. (p. 294)

As autoras lembram-nos que os jovens são geralmente vistos como "sujeitos em constante 'perigo' social para os quais é necessário tomar uma série de medidas socioeducativas” (p. 288). Essa percepção, salvacionista, dizem as pesquisadoras, foi confirmada pelos próprios oficineiros com os quais elas trabalharam no desenvolvimento de ações de extensão de uma universidade.

A definição de Gohn (2010) contrasta com a do CBO (2010). Nesta, o educador social é visto quase como um agente pacificador, que atende demandas e lida com sujeitos vulneráveis e de comportamentos voláteis, evidenciando o caráter de prevenção. Para Gohn, o educador social é aquele que, pela sua atuação e inserção em uma comunidade/território, consegue ressignificar o tecido social local, produzindo a partir dos saberes ali disponíveis, sempre comprometido com a ampliação da cidadania dos sujeitos envolvidos em sua prática.

Para Ude (2014), “[o] educador social é um profissional que atua no campo da educação social7 , que é um dos âmbitos das ciências da educação" (p. 67). E completa, dizendo que "a presença de educadores-militantes identificados com movimentos sociais, sindicais e populares, entre outros" (p. 68), buscava uma ruptura com contextos alienantes, objetivando criar condições para o aparecimento de sujeitos críticos e independentes. Essa definição se aproxima mais da posição defendida por Gohn (2010) e identifica, também, o caráter ativo e transformador da realidade, possibilitando aos sujeitos a autoria de suas histórias e a consolidação de suas cidadanias.

O autor acrescenta ainda que "não se trata de uma postura anti-escola, mas uma proposta que visa articular os processos escolares às questões sociopolíticas e à vida comunitária dos sujeitos" (Ude, 2014, p. 71). Nesse trecho, per-

7. Nesta citação, Ude não está se referindo à pedagogia social. Ele distingue as duas concepções. Para maiores compreensões dessa distinção, ver a referência bibliográfica. 
cebemos a relação atribuída por Ude (2014), na mesma linha de Gohn (2010), do vínculo do educador social ao território/comunidade onde ele desenvolve sua atuação.

Segundo Ude (2014), a atuação do educador social é ampla, e "trata-se de um campo transdisciplinar e intersetorial, que agrega a perspectiva de intersaberes (científico, popular, religioso, familiar, tribal, comunitário etc.)" (p. 71). A perspectiva de conexão de saberes formais/escolares com os comunitários/populares é valiosa a Ude, assim como o será na descrição das intencionalidades do PME.

O campo de atuação, mesmo amplo e multifacetado, do educador social, se concretiza nos domínios da educação não formal, caracterizada por Libâneo (2010) como "aquelas atividades com caráter de intencionalidade, porém com baixo grau de estruturação e sistematização, implicando certamente relações pedagógicas, mas não formalizadas" (p. 89). 0 estudioso nos diz ainda como a educação não formal também pode acontecer no ambiente escolar: “[n]a escola são práticas não-formais as atividades extra-escolares que provêem conhecimentos complementares, em conexão com a educação formal” (p. 89). 0 trabalho do educador social se caracteriza como prática da educação não formal, visto que tem uma intencionalidade (não sendo, portanto, educação informal), e também é uma atividade que não prevê a sistematização metodológica dos conhecimentos (excluindo a via da educação formal); a educação não formal se dá no intermédio e na relação dos saberes formalizados e escolares com os saberes comunitários e populares.

Constatamos uma dificuldade de definir âmbito e espaços de atuação, perfil, saberes, fazeres, natureza e fim do ofício do educador social. "Essas nuanças conceituais evidenciam a dificuldade de se produzir uma unidade teórica acerca destas temáticas, já que apresentam aspectos epistemológicos, ontológicos e axiológicos de matrizes distintas, bem como implicações políticas e ideológicas diversas” (Ude, 2014, p. 67).

Discorremos acima sobre o que se pode encontrar, tanto na literatura sobre o tema como nos documentos aqui usados como referência. Todavia, Gohn (2010) fornece uma significação viável:

em síntese, o Educador Social numa comunidade atua nos marcos de uma proposta socioeducativa, de produção de saberes a partir da tradução de culturas locais existentes e da reconstrução e ressignificação de alguns eixos valorativos, tematizados segundo o que existe, em confronto com o novo que se incorpora. .... Nos territórios onde há o trabalho do(a) Educador(a) Social com a comunidade, se poderá construir ou reconstruir o tecido social existente, bastante fragmentado na atualidade. (p. 55) 
Entendida a sinonímia, aqui defendida, do monitor como um educador social, voltamos agora à questão central que conduz o debate deste trabalho: Qual o perfil da figura intitulada como "monitor” no Programa Mais Educação?

De todos os documentos oficiais desse Programa, ${ }^{8}$ existem somente três passagens relativas à natureza e à caracterização da figura do monitor.

A primeira delas ocorre no "Educação integral: texto referência para o debate nacional”, que dispõe que as práticas educativas extraescolares “associadas às orientações dos Parâmetros Curriculares Nacionais e ao projeto político-pedagógico de cada escola, podem ser desenvolvidas por monitores - oficineiros e voluntários - selecionados entre os moradores e integrantes das entidades parceiras que participam de capacitações periódicas" (MEC, 2009, p. 19).

Essa primeira demarcação é importante para entendermos a natureza do trabalho pensado para o monitor - o de proximidade com a comunidade e com o território - e nos permite reafirmar a semelhança de função entre este e o educador social.

A segunda aparição do termo acontece na Resolução 34/2013 do Conselho Deliberativo do Fundo Nacional de Desenvolvimento da Educação. Encontra-se ali registrada a seguinte definição, em seu artigo 4ํㅜㄹ alínea II, parágrafo 1ํㅜ :Para os fins desta resolução, considerar-se-ão monitores os responsáveis pela realização das atividades previstas" (Resolução BR n. $\stackrel{0}{34}$, de 6 de setembro de 2013, 2013, p. 5). Aqui se tem uma atribuição de tarefa/função: os monitores são entendidos como os

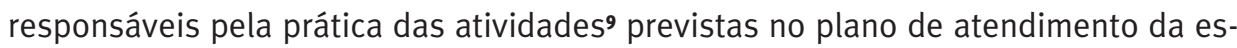
cola do Programa Mais Educação.

A última das referências ocorre no "Manual Operacional de Educação Integral” (MEC, 2013), onde se registra que

[o] trabalho de monitoria deverá ser desempenhado, preferencialmente, por estudantes universitários de formação específica nas áreas de desenvolvimento das atividades ou pessoas da comunidade com habilidades apropriadas, como, por exemplo, instrutor de judô, mestre de capoeira, contador de histórias, agricultor para horta escolar, etc. Além disso, poderão desempenhar a função de monitoria, de acordo com suas competências, saberes e habilidades, estudantes da EJA e estudantes do ensino médio. (p. 23)

Essa passagem nos traz novos elementos de análise e, por isso, se fez essencial neste artigo. Ao
8. Até o dia 9 de maio de 2014 .

9. As atividades aqui citadas são aquelas compreendidas como extraescolares, isto é, as dos saberes comunitários e populares. 
denotar preferência por estudantes universitários das áreas específicas, o Programa reforça a sua essência de sinergia de saberes escolares e comunitários. Ao mesmo tempo, abre o leque de compreensão de quem é elegível a uma identificação de monitor e, assim, fala das "pessoas da comunidade com habilidades apropriadas" (MEC, 2013, p. 23). Isso nos sugere a compreensão de que saberes diferentes demandam agentes diferentes, como explicitado na citação do mestre de capoeira e do agricultor para a horta, que possuem um saber prático da atividade.

Um último ponto ao qual gostaríamos de chamar atenção é a referência aos estudantes da Educação de Jovens e Adultos e do Ensino Médio como elegíveis também para atuar como monitores, o que reforça o conceito desenvolvido de educador social e vai ao encontro da não exigência de formação para atuar como educador social, descrita no CBO. Essa elucidação no documento confirma a inexistência de critérios formativos, ou a exigência de uma formação mínima a ser requerida para atuar como monitor nas atividades de extensão da jornada escolar.

Parece existir uma tensão entre as proposições contidas nos documentos do Programa Mais Educação. Fala-se de uma preferência ao estudante universitário e, portanto, ao saber especializado de uma área do conhecimento. Entretanto, essa enunciação se contradiz, ao possibilitar a estudantes da EJA e do Ensino Médio o exercício da monitoria, já que esses ainda não completaram sua educação básica. Quanto às pessoas da comunidade, portadores dos saberes locais e comunitários, sua formação escolar é um mistério na documentação. Na prática, se exige pouco, ou quase nada, das pessoas da comunidade, em termos de escolarização. 0 foco da sua atuação deve ser o saber prático, a técnica, longe do perfil preferencial - o universitário.

\section{Contextualizando o monitor de Jataí (G0) no quadro da aná- lise teórica}

Nesta seção, apresentaremos uma visão panorâmica do perfil dos monitores que atuam no Programa Mais Educação, nas escolas municipais da cidade de Jataí, sudoeste goiano, e procederemos a uma comparação entre os dados levantados, via questionário, e a revisão de literatura realizada.

Para o levantamento do perfil desse novo ator, foi elaborado um questionário, o qual foi respondido por 32 monitores - todos os educadores sociais que desenvolvem atividades no PME do município de Jataí-GO, uma vez que atuam em mais de uma escola. 
O questionário aplicado teve por objetivo fornecer os dados necessários para traçarmos uma contextualização dos monitores da região específica já citada, além de possibilitar a conferência com a literatura.

Do total de 32 monitores atuantes em Jataí, 25 são mulheres e 7, homens, representando $76 \%$ e $24 \%$, respectivamente, de idades variadas, como apresentado no Gráfico 1.

Gráfico 1 - Idade dos monitores que atuam no Programa Mais Educação em Jataí (2014)

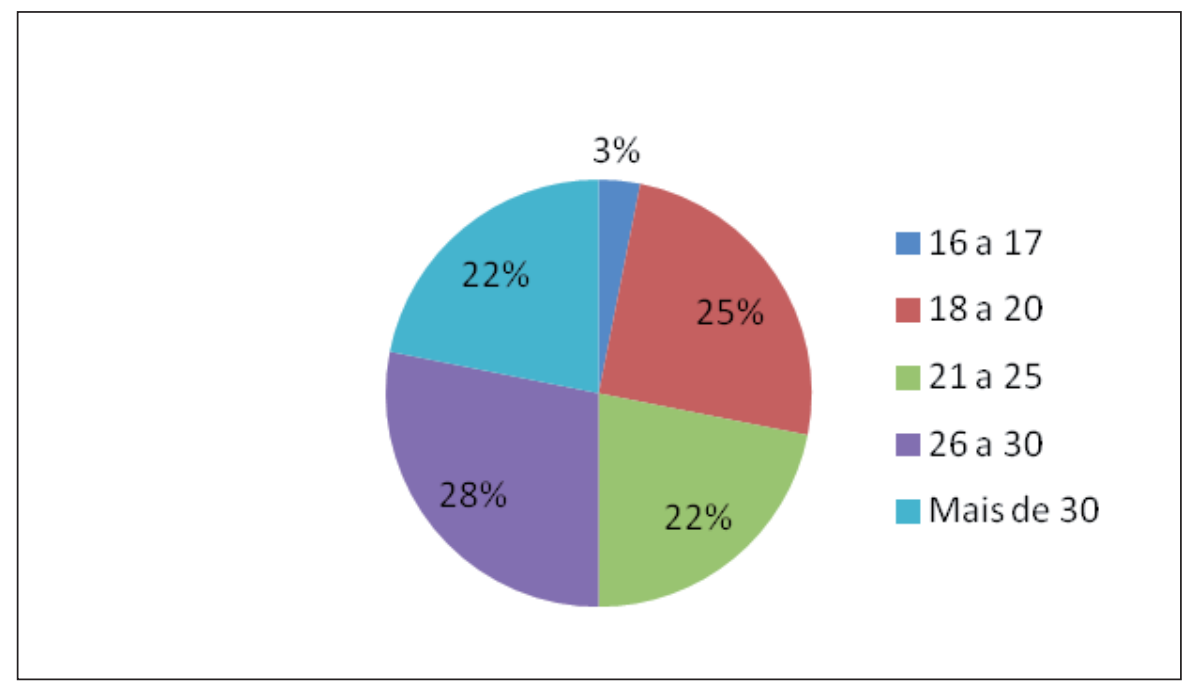

Fonte: Questionários elaborados pelos autores

Os monitores são, em sua maioria, mulheres, e a representação masculina é, proporcionalmente, bem menor. Suas idades são variadas, e podemos constatar um equilíbrio entre as faixas etárias, se descartada a faixa ente 16 e 17 anos de idade, com um monitor apenas. Os monitores com mais de 30 anos são 7, e representam $22 \%$ do total, apontando a inserção de pessoas mais velhas, o que descaracteriza o exclusivismo do jovem universitário, o público preferencial para essa atuação.

A inexistência de requisito de grau ou formação escolar para atuar como educador social, como apontado pela literatura, se confirmou com os sujeitos que atuam na monitoria do Mais Educação em Jataí, como representado no Gráfico 2. 
Gráfico 2 - Nível de escolaridade dos monitores do Programa Mais Educação de Jataí-GO (2014)

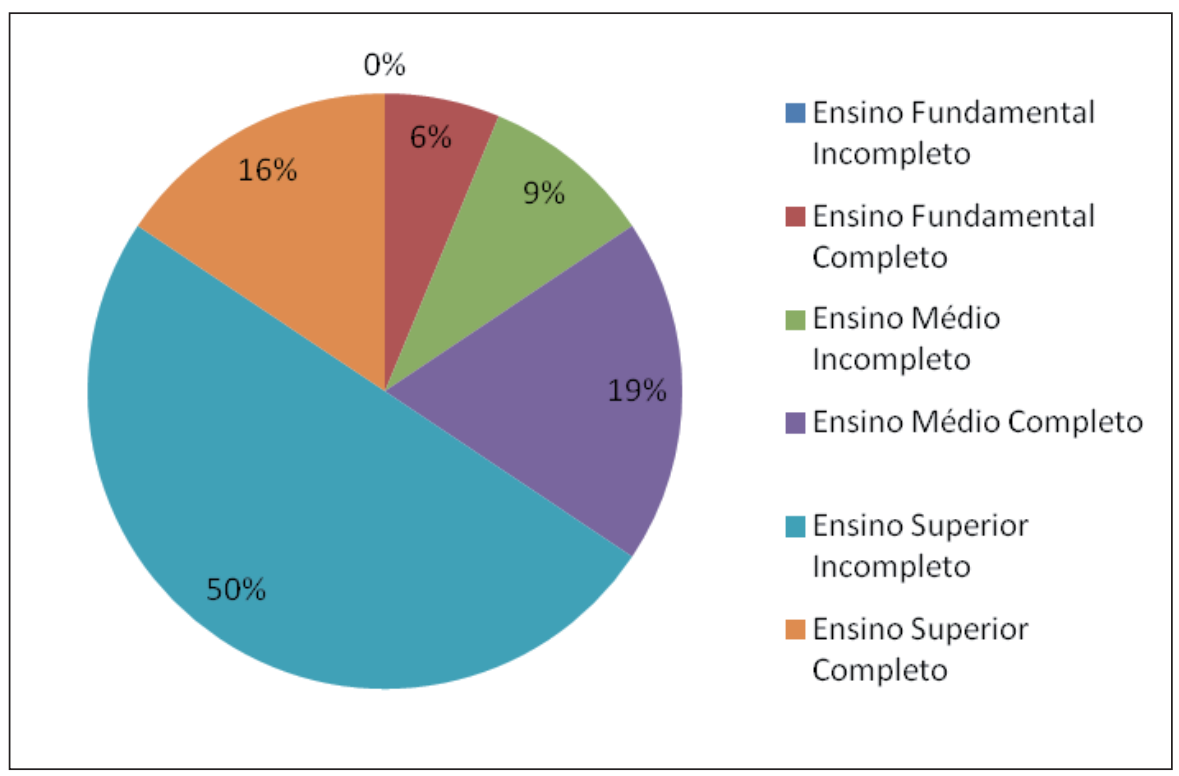

Fonte: Questionários elaborados pelos autores

Nenhum deles está cursando o Fundamental, enquanto 2, ou 6\%, o finalizaram, mas ainda não ingressaram no Ensino Médio. Seis dos monitores, 19\% do total, já concluíram seus estudos do Ensino Médio, e 16\% (5 pessoas) já terminaram o Ensino Superior. Ou seja, em Jataí, metade dos educadores sociais atuantes no PME representa o público não preferencial, de acordo com o documento oficial, para atuar no programa, enquanto os outros 50\%, 16 monitores, são estudantes de graduação.

Embora, à primeira vista, nos pareça um cenário equilibrado, ao somarmos os estudantes do Ensino Superior e aqueles que já concluíram essa etapa de seus estudos, constatamos 21 sujeitos, ou seja, 66\% dos monitores. Aqui, chamamos a atenção para a prevalência do status que os saberes acadêmicos ocupam na proposta de conjugação com os saberes comunitários e populares. Contudo, como preconizado pelo Mais Educação, foi resguardada a participação de outros sujeitos, que não os universitários e concluintes da graduação.

Do grupo dos monitores que estão em algum curso superior universitário, 68\% estão matriculados na modalidade licenciatura e 32\% no bacharelado, distribuídos em diversos cursos, como expõe o Gráfico 3. 
Gráfico 3-Cursos superiores dos monitores universitários do

Programa Mais Educação de Jataí-GO (2014)

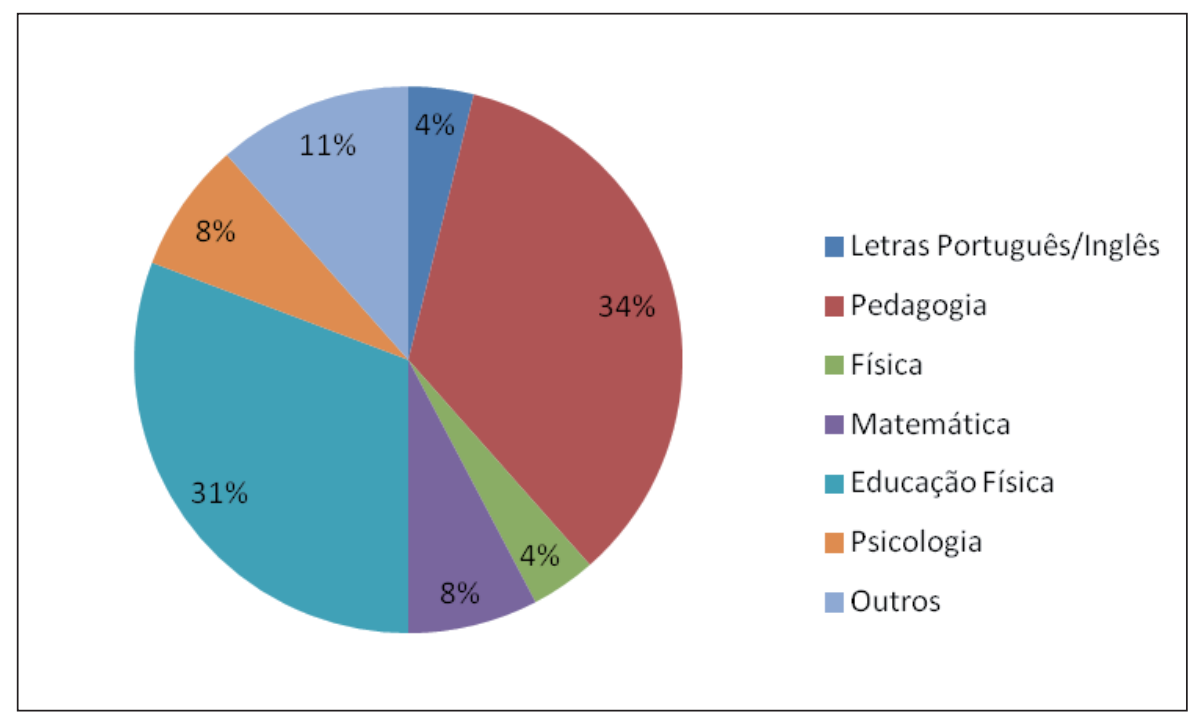

Fonte: Questionários elaborados pelos autores

Conforme ilustrado no gráfico, é forte a presença dos universitários de Pedagogia, nove deles; e de Educação Física - oito, atuando como educadores sociais no PME. Esses índices são indicativos da própria formatação do programa, que apregoa a inserção de atividades de acompanhamento pedagógico, esportes e lazer, e de arte e cultura. Desse modo, graduandos em Pedagogia são requisitados para as atividades de "reforço", e os universitários de Educação Física, para as atividades esportivas e de lazer. 0 universitário de Letras, um, e os de Matemática, dois, também foram chamados a desenvolver atividades de acompanhamento pedagógico. De novo, há forte indício da representatividade dos saberes acadêmicos no conjunto de saberes possíveis dentro do desenvolvimento das ações propostas como estratégia de ampliação da jornada escolar. Assim, mesmo resguardada a participação de pessoas da comunidade, a representatividade de acadêmicos e egressos é predominante, em vista dos outros indicadores.

Quando perguntamos aos monitores se o PME era sua primeira experiência profissional, 31\% responderam que sim, ou seja, 10 pessoas; e 69\% já tinham atuado profissionalmente anteriormente. Dos que responderam já ter experiência profissional, 
66\%, 23 monitores já haviam atuado em alguma área da educação. Vejamos como se deu essa atuação anterior. 0 Gráfico 4 ilustra esses dados.

Gráfico 4 - Atuação profissional na educação anterior à atuação como monitor no Programa Mais Educação de Jataí-Goiás (2014)

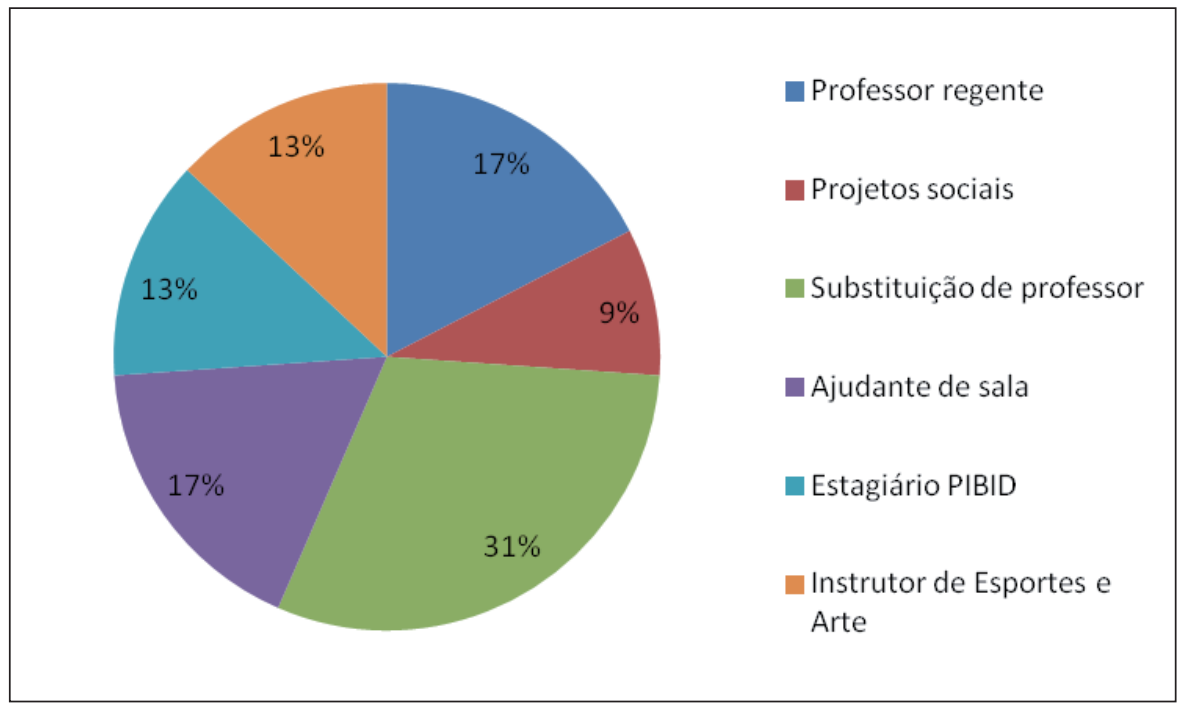

Fonte: Questionários elaborados pelos autores

A diversidade de atuações anteriores dos monitores no campo da educação é evidente. A maioria dos educadores sociais, 31\%, já havia substituído algum professor em salas de aula, sete deles. Dezessete por cento eram professores regentes e hoje estão atuando como educadores sociais, e outros 17\% já atuaram como ajudantes de sala, somando oito monitores que já haviam tido alguma experiência de médio ou longo prazo com a prática da escolarização. Três monitores já haviam sido bolsistas do PIBID e outros três trabalharam no campo de instrução de esporte e arte, com atividades de capoeira, dança, pintura e grafite.

Acreditamos faltar aos monitores uma formação, com clareza técnica e política sobre a definição do âmbito de sua ação. Na maioria das vezes, o que constatamos foi a crença de que o PME, por ser desenvolvido em um espaço da escola, é um programa de educação formal. Contudo, essa crença não se confirma na literatura e nos documentos oficiais. Não existem, no âmbito do programa, currículo, metodologias e estratégias definidas, ou seja, o PME não pressupõe a sistematização dos saberes, característica fundamental e intrínseca da prática formal de educação. 
A concepção dos monitores entrevistados, quando inqueridos sobre o que entendiam por oficina, se aproxima muito da definição de monitor como aquele que desenvolve as atividades previstas. 0 Gráfico 5 mostra esse resultado.

Gráfico 5 - Percepção de oficina segundo os monitores do Programa Mais Educação de Jataí-GO (2014)

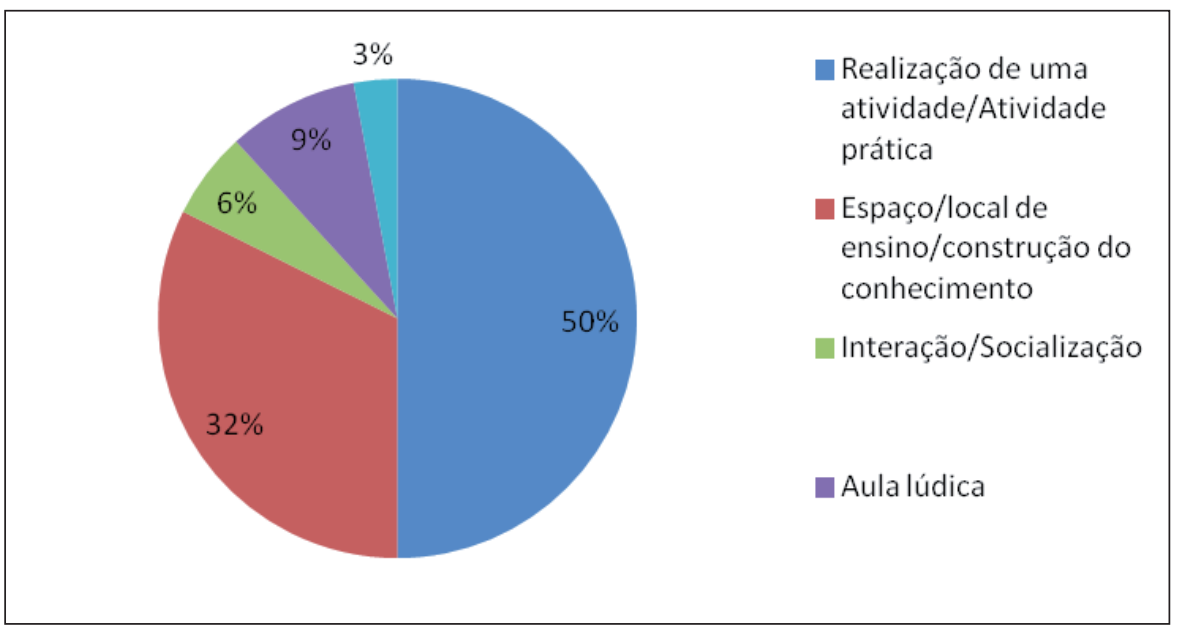

Fonte: Questionários elaborados pelos autores

Dezessete monitores, $50 \%$ dos que responderam à questão, afirmaram que entendiam as oficinas temáticas do PME como conjuntos de atividades práticas. A ideia de realizar a atividade proposta está fortemente presente no apontamento dos monitores, revelando que sua percepção vai ao encontro do definido em resolução pelo FNDE, apontada acima. Por outro lado, 11 deles, 32\%, compreendem a oficina como espaço de ensino e construção do saber e 15\%, 5 pessoas, apontaram que a oficina é socialização ou ludicidade.

Indagamos ainda aos monitores participantes deste estudo se eles consideravam importante a formação complementar ofertada pelo PME, e todos os 32 responderam positivamente. Em seguida, perguntamos qual seria a importância do Programa, e as respostas nos remeteram às características, já anunciadas, do trabalho do educador social de caráter preventivo. Eis o que revela o Gráfico 6: 
Gráfico 6 - Importância do Programa Mais Educação, segundo os monitores de Jataí-GO (2014)

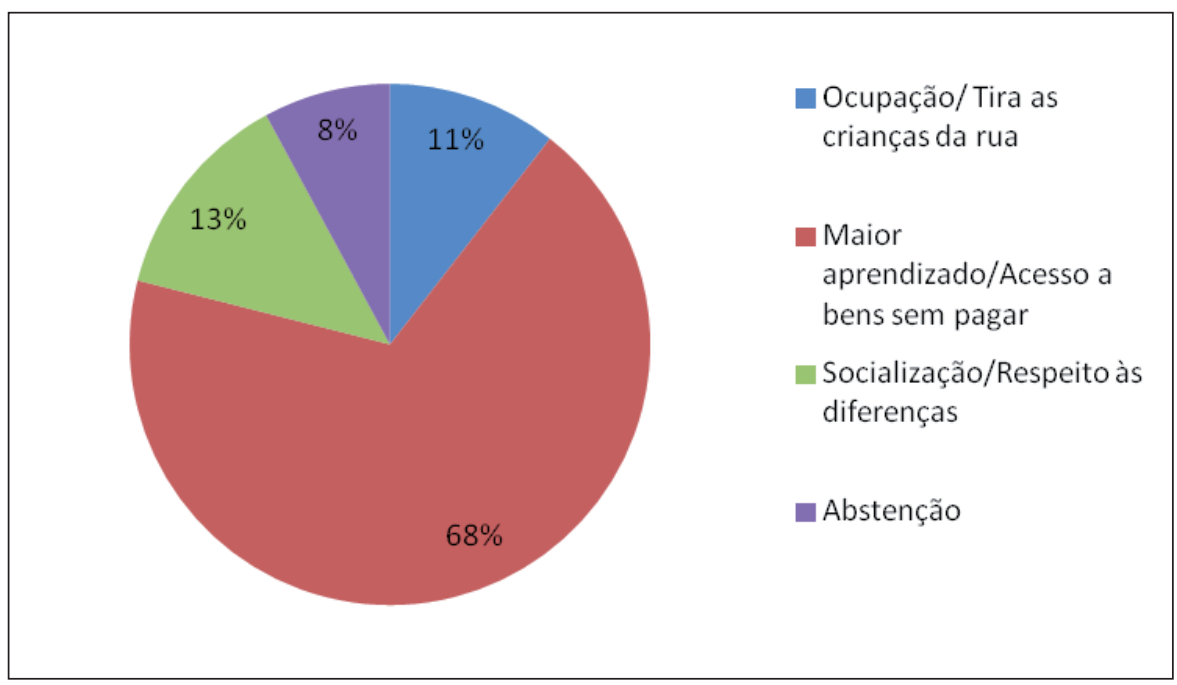

Fonte: Questionários elaborados pelos autores

Cinco monitores, $11 \%$, entendem que o programa, ao ampliar o tempo de permanência na escola, fornece proteção social às crianças, dando-lhes uma ocupação e evitando que estejam nas ruas. Tal entendimento ilustra o caráter essencialmente preventivo, e com pessoas em situação de risco, tal qual disposto no CBO e aqui explorado.

Os monitores que disseram que o PME proporciona maior aprendizado e acesso gratuito a bens apontam a via educativa como eixo das ações desenvolvidas, porém ainda impregnada de assistencialismo. Já os que afirmaram ser a socialização a preponderância do programa nos parecem se furtar ao caráter de finalidade, ou seja, não reconhecem, ao menos explicitamente, o objetivo de sua própria ação. Esse quadro de tensões e de indefinições não é diferente daquele encontrado na literatura quanto à natureza específica do trabalho do educador social, também tensionado entre o assistencialismo, a vulnerabilidade social e as práticas educativas.

As revisões de literatura, a leitura dos documentos oficiais, o diagnóstico das percepções dos monitores atuantes nos levam a crer que o Programa Mais Educação se presta muito mais à prática de proteção/assistência social do que educativa. Portanto, não qualifica a proposta de educação integral, considerada a meta do 
Programa, mas revela um caráter de acolhimento social. Além disso, o programa prevê a articulação dos programas e dos projetos já existentes do governo federal com a prática educativa das escolas. Pretende, assim, uma otimização dos serviços prestados, articulados e direcionados às escolas; implica mais em redução do que em ampliação.

Assim, os dados encontrados em Jataí, Goiás, reforçam as considerações conceituais acerca do monitor, de sua autoconcepção e do programa; de sua atuação; e das tensões constitutivas de um grupo que ainda luta para definir sua identidade profissional, como nos lembra Garcia (2008).

Encontramos também, na literatura e nos documentos do PME, uma certa invisibilidade do sujeito monitor/educador social. Dele muito pouco se fala, principalmente se o tomarmos como o agente executor das atividades de um programa tão amplo e ambicioso. Logo, as políticas públicas, em especial o Programa Mais Educação, precisam melhor elucidar quem é esse sujeito, o que ele sabe e como faz o que sabe, e atentar para ele e sua prática.

À guisa de uma conclusão, ainda que não seja final e muito menos total, esperamos ter contribuído com a compreensão do perfil, do papel, das funções e das atribuições dos educadores que se dedicam às práticas educativas não escolares, em especial os monitores que atuam no PME. Para isso, buscamos elucidar o termo "educador social", desenvolvendo o raciocínio de que os monitores podem ser compreendidos e categorizados como educadores sociais, depois de analisadas suas práticas e as referências teóricas que nos deram suporte neste trabalho. Ambicionamos ainda ter colaborado de alguma forma com a discussão do perfil do monitor dentro do Programa Mais Educação e ter incentivado o interesse de mais pesquisadores por maiores estudos sobre a educação não formal, o educador social e seus fazeres. 


\section{Referências bibliográficas}

Garcia, V. A. (2008, 1ํ semestre). 0 papel do social e da educação não-formal nas discussões e ações educacionais. Ciências da Educação, 10(18), 65-98.

Gohn, M. da G. (2010). Educação não formal e o educador social: atuação no desenvolvimento de projetos sociais. São Paulo: Cortez.

Libâneo, J. C. (2010). Pedagogia e pedagogos, para quê? (12a ed.). São Paulo: Cortez.

Maraschin, C., Chassot, C. S., \& Gorczevski, D. (2006). Saberes e práticas de oficineiros - análise de uma cognição situada. Psico, 37(3), 287-296.

Ministério da Educação - MEC. (2009). Secretaria de Educação Continuada, Alfabetização e Diversidade. Educação integral: texto referência para o debate nacional (Série Mais Educação). Brasília: Autor.

Ministério da Educação - MEC. (2011). Secretaria de Educação Básica. Caminhos para elaborar uma proposta de educação integral em jornada ampliada (Série Mais Educação). Brasília: Autor.

Ministério da Educação - MEC. (2013). Secretaria de Educação Básica. Manual operacional de educação integral. Brasília: Autor.

Ministério do Trabalho e Emprego - MTE. (2010). Classificação brasileira de ocupações: $C B O$ (за ed.). Brasília: Autor.

Ramos, M. F., \& Roman, A. (2011). Educadores sociais: a importância da formação na implementação de tecnologias sociais. Brasília, DF: Fundação Banco do Brasil.

Ude, W. (2014, janeiro/fevereiro). Educador social. Presença pedagógica, 20(115), 66-72.

\section{Legislação}

Decreto $B R$ no 7.083 , de 27 de janeiro de 2010. Dispõe sobre o Programa Mais Educação. Diário Oficial da União [da República Federativa do Brasil], Brasília, DF, n.․18-A, 27 jan. 2010. Edição extra, seção 1, pp. 2-3.

Resolução $B R$ n.ํㅜ 34, de 6 de setembro de 2013. Ministério da Educação. Fundo Nacional de Desenvolvimento da Educação. Retirado de: http://www.fnde.gov.br/fnde/ legislacao/resolucoes.

Submetido à avaliação em 18 de março de 2015; aceito para publicação em 02 de maio de 2015. 